\title{
Insensitivity of the Hippocampus to Environmental Stimulation during Postnatal Development
}

\author{
Nicholas S. Waters, ${ }^{1}$ Anna Y. Klintsova, ${ }^{2}$ and Thomas C. Foster ${ }^{1}$ \\ ${ }^{1}$ Department of Psychology, University of Virginia, Charlottesville, Virginia 22903, and ${ }^{2}$ Beckman Institute, University of \\ Illinois, Urbana-Champaign, Urbana, Illinois 61801
}

\begin{abstract}
Development of cortical sensory systems is influenced by environmental experience during "sensitive periods," before onset of behavioral function. During these periods, synaptic plasticity is observed, and neuronal function shows increased responsiveness to environmental stimulation. Because the hippocampus is late to develop, and because it demonstrates synaptic plasticity before the onset of behavioral function, this experiment was designed to determine whether, like the sensory cortices, the hippocampus undergoes a period of enhanced responsiveness to the environment. Rats at three ages [postnatal day 16 (P16), P23, and P30] were tested on a hippocampally dependent task, spontaneous alternation, and exposed to a novel environment. They were then killed and processed for immunocytochemistry to Fos or for in vitro electrophysiology in hippocampal area CA1. Age-matched control subjects were killed immediately after removal from the home cage. Sponta-
\end{abstract}

neous alternation was only observed in the oldest (P30) animals. In these same animals, the environmental manipulation resulted in an increase in Fos-like immunoreactivity (FL-IR), relative to controls, and a decrease in the ability to induce long-term potentiation (LTP). In P16 and P23 animals, the environmental manipulation resulted in no differences in hippocampal FL-IR or LTP. These results suggest that, rather than showing increased responsiveness to the environment at these ages, the hippocampus is environmentally insensitive and that it is isolated from the effects of environmental stimuli. The hippocampus, a neural region important for higher cognitive function, may develop via a mechanism different from those observed in the primary sensory cortices.

Key words: hippocampus; rat; LTP; c-fos; immunocytochemistry; electrophysiology; spontaneous alternation; development
In the cortical sensory systems, patterns of synaptic connectivity are formed postnatally. Before the emergence of behavioral function, the organization of synaptic contacts is influenced by sensory experience during a postnatal "sensitive period," resulting in permanent changes in connectivity and function (see Shatz, 1990, 1996; Goodman and Shatz, 1993; Fox, 1995). During this sensitive period, the primary sensory cortices show enhanced synaptic plasticity (Tsumoto et al., 1987; Komatsu et al., 1988; Perkins and Teyler, 1988; Crair and Malenka, 1995; Kirkwood et al., 1995) and increased responsiveness to environmental stimulation (Rosen et al., 1992; Beaver et al., 1993; Mower, 1994). This evoked-activity dependent mechanism serves as a model of postnatal neural development; however, its applicability to cognitive development is unknown.

Like the sensory cortices, the hippocampus undergoes a period of postnatal development, and behavioral function does not emerge until this period is complete. For example, young rats do not show spontaneous alternation on a Y-maze, although they explore at a rate similar to that of mature animals (Douglas, 1975). Spontaneous alternation, like other behaviors that seem to require hippocampal function in adult rats, emerges after $\sim 3$ weeks of age (Douglas, 1975; Moye and Rudy, 1985; Castro et al., 1987; Rudy et al., 1987; Green and Stanton, 1989; Kraemer and

Received May 12, 1997; revised July 16, 1997; accepted July 29, 1997.

This work was supported in part by National Institutes of Health Training Grant HD07323 and Grants NS31830 to T.C.F. and NS10115 to N.S.W. We thank Dr Peter C. Brunjes for providing equipment for some of this work and Dr. Lori L. Badura for aid with the immunohistochemical protocols.

Correspondence should be addressed to Dr. Thomas C. Foster, Department of Psychology, 102 Gilmer Hall, University of Virginia, Charlottesville, VA 22903.

Copyright (C) 1997 Society for Neuroscience 0270-6474/97/177967-07\$05.00/0
Randall, 1992, 1995; Rudy, 1993; Rudy and Morledge, 1994). Much of hippocampal synaptogenesis occurs postnatally (Crain et al., 1973; Stirling and Bliss, 1978; Bayer, 1980; Amaral and Dent, 1981; Baudry et al., 1981; Amaral and Kurz, 1985), and hippocampal synapses exhibit plasticity before the emergence of mature behavioral function (Harris and Teyler, 1984; Muller et al., 1989; Bekenstein and Lothman, 1991). It is the maturation of these anatomical and physiological properties that is thought to underlie the emergence of adult-like behavior (Dumas and Foster, 1995). Therefore, the postnatal development of the hippocampus seems similar to that of the primary sensory cortices; it undergoes a period of synaptic plasticity before the emergence of mature behavioral function.

These developmental similarities suggest that the hippocampus may also undergo a postnatal sensitive period, during which neuronal activity shows increased responsiveness to environmental stimulation. In the current study, Fos immunocytochemistry and in vitro electrophysiological recording were used to measure this responsiveness in rats before and after the emergence of hippocampally dependent behavior. Environmental experience in the adult rat produces an increase in expression of the immediate early gene c-fos and its protein product Fos (Melia et al., 1994; Hess et al., 1995; Grimm and Tischmeyer, 1997) and a decrease in the expression of long-term potentiation (LTP) (Foy et al., 1987; Shors et al., 1989; Diamond et al., 1990; Shors and Thompson, 1992; Shors and Dryver, 1993; Diamond and Rose, 1994). If the immature hippocampus demonstrates increased sensitivity to environmental stimuli during this postnatal period, then the effects of environmental stimulation on these two measures should be increased before the onset of behavioral competence. 


\section{MATERIALS AND METHODS}

Subjects. Sprague Dawley rats were bred and born in our colony; progenitors were received from Hilltop Labs. All animals were housed on a reverse $12 \mathrm{hr}$ light/dark schedule (lights off at 9:00 A.M.) and had food and water ad libitum. On postnatal day 1 ( $\mathrm{P} 1$; birth equals $\mathrm{P} 0)$, litters were culled to 10 pups, with not less than two females per litter. On P21, subjects were weaned and pair-housed with littermates in standard cages.

For the anatomical study, two males [one experimental (EXP) and one control $(\mathrm{CON})]$ from each litter were killed at each of three ages (P16, P23, and P30). After weaning, EXP and CON pairs consisted of cagemates. For physiological studies, EXP and CON subjects were killed at the same ages, but subjects were assigned to groups and ages without regard to litter; each litter contributed to more than one condition or age group. In both experiments, EXP animals were tested for spontaneous alternation on the $\mathrm{Y}$-maze and exposed to a novel environment (see below) before killing; CON animals were killed immediately after removal from the home cage.

Behavioral testing. The Y-maze, consisting of black Plexiglas, had three evenly spaced arms $\left(50 \mathrm{~cm}\right.$ long $\times 15 \mathrm{~cm}$ high $\times 14 \mathrm{~cm}$ wide; $120^{\circ}$ separation between arms) and contained $\sim 10 \mathrm{~cm}$ of water $\left(24^{\circ} \mathrm{C}\right)$ throughout. EXP subjects were placed at the end of arm 1 and allowed to explore for $5 \mathrm{~min}$. The number and sequence of arms entered were recorded. The dependent variables were activity, defined as the number of arms entered, and percent alternation, calculated as the number of alternations (entries into three different arms consecutively) divided by the total possible alternations (i.e., the number of arms entered minus 2) and multiplied by 100 . After behavioral testing, animals were placed in a novel environment, consisting of an enclosure containing objects such as a coffee can, wood blocks, and other small boxes (Foster et al., 1996), for $55 \mathrm{~min}$ and then killed (total time was $1 \mathrm{hr}$ after the onset of behavioral testing). All animals were tested or killed at the onset of the dark period.

Immunocytochemistry. Animals were killed by overdose with pentobarbitol and transcardially perfused with a heparinized PBS solution, $\mathrm{pH} 7.4$, followed by a cold fixative of $4 \%$ paraformaldehyde and $0.2 \%$ glutaraldehyde in PBS for $30 \mathrm{~min}$ and then by $10 \%$ sucrose and fixative. After perfusion, the brains were removed and cryoprotected in $30 \%$ sucrose and then were frozen. Sections $(35 \mu \mathrm{m})$ were obtained using a cryostat, rinsed in Tris-buffered saline (TBS), pH 7.6, and processed free-floating for immunocytochemistry to Fos. Blocking steps were performed with $0.9 \% \mathrm{H}_{2} \mathrm{O}_{2}$ solution in TBS (10 min) and with $10 \%$ normal goat serum (NGS) and $0.75 \%$ Triton X-100 (TX) in TBS (60 $\min )$. The primary antibody was an affinity-purified rabbit polyclonal anti-Fos antibody, raised against a peptide corresponding to amino acids 3-16 of human Fos (Santa Cruz Biotechnology, Santa Cruz, CA; $1: 100 ; 2 \mathrm{hr}$ ); this commercially available antibody is specific to Fos and noncross-reactive to Fos-B, Fos-related antigen 1 (FRA-1), and FRA-2. The secondary antibody was a goat anti-rabbit antibody (Vector Laboratories, Burlingame, CA; 0.3\%; $90 \mathrm{~min}$ ). Visualization was achieved using the ABC method (Vector Laboratories) and a 3,3diaminobenzidine (DAB) substrate enhanced with nickel ammonium sulfate. Antibody and ABC solutions were prepared in a $1 \%$ NGS and $0.75 \%$ TX TBS solution. Between each step, sections were washed three times for $5 \mathrm{~min}$ each in TBS.

Fos-like immunoreactivity (FL-IR) in the left and right sides of each of two sections from each subject was quantified using an Olympus Cue-2 densitometry system to produce regional counts of immunopositive nuclei in four regions of the hippocampus (areas CA3 and CA1, the dentate gyrus, and the subiculum), one cortical region (the perisplenial cortex dorsal to the hippocampus), and one thalamic nucleus [the paraventricular nucleus (PVT)]. For each region, a rectangle was set to include the highest number of immunopositive nuclei in the area, and the total number of immunopositive nuclei within the rectangle was determined from the transformed black and white image. The analyses were performed blind to the age or condition of the subject. For all areas, the four measures were transformed to activation indices, calculated as the number of immunopositive nuclei per unit area, and compressed into a single index per area per subject. The pooled indices yielded significant reliability (Denenberg, 1979) and were used for all analyses. Because of tissue damage, four subjects (one P30 CON and three P23 CONs) were not included in the analysis for the perisplenial cortex; the same four and one P16 CON were excluded from the PVT analyses.

In vitro electrophysiology. Subjects were deeply anesthetized with methoxyflurane (Metophane) and decapitated. The brains were rapidly extracted, and the hippocampi were dissected out. Hippocampal slices $(450-500 \mu \mathrm{m})$ were cut parallel to the alvear fibers with a tissue chopper and transferred to a standard Haas-style recording chamber (Haas et al., 1979). Slices were perfused $(1 \mathrm{ml} / \mathrm{min})$ at $32^{\circ} \mathrm{C}$ with oxygenated artificial $\mathrm{CSF}$ (aCSF) containing (in $\mathrm{mM}$ ): $\mathrm{NaCl} 124, \mathrm{KCl} \mathrm{2}, \mathrm{KH}_{2} \mathrm{PO}_{4} 1.25$, $\mathrm{MgSO}_{4} 2, \mathrm{CaCl}_{2} 2, \mathrm{NaHCO}_{3} 26$, and glucose 10 . Humidified air $(95 \%$ $\mathrm{O}_{2} / 5 \% \mathrm{CO}_{2}$ ) was continuously blown over the slices.

Extracellular field potentials were recorded with glass micropipettes (4-6 M $\Omega$ ), filled with aCSF, and were localized to CA1 dendrites in the middle of st. radiatum. The stimulating electrode consisted of a pair of insulated platinum-iridium wires twisted together with the tips exposed and was positioned $\sim 1 \mathrm{~mm}$ away from the dendritic recording electrode, toward CA3. Biphasic constant current stimuli (100 $\mu \mathrm{sec}$ in duration) were delivered every $30 \mathrm{sec}$. The signals were amplified 100 times, filtered between $1 \mathrm{~Hz}$ and $1 \mathrm{kHz}$, and stored on computer disk for off-line analysis. Baseline stimulation intensity was set to elicit a $1 \mathrm{mV}$ response. Before the induction of LTP, recording was performed to produce at least $10 \mathrm{~min}$ of stable baseline. For LTP induction, high-frequency stimulation (two $1 \mathrm{sec}$ bursts of $100 \mathrm{~Hz} ; 10 \mathrm{sec}$ between bursts) was delivered. Recording continued for at least $30 \mathrm{~min}$. The dependent variable was the slope of the EPSP, measured by a computer program (Datawave, Boulder, $\mathrm{CO}$ ) that determined the maximum slope of the descending portion of the EPSP by linear regression.

For inclusion in the final analysis, the responses from a slice were required to show observable $(>25 \%)$ increases in EPSP slope immediately after tetanus (i.e., post-tetanic potentiation). Data were collected from up to three slices per animal, and all slices that met these criteria from each animal were averaged to produce a single record per animal. For final analyses, the EPSP slopes from the baseline and the posttetanization recording periods were transformed into a percent of baseline (determined for the average of the last $10 \mathrm{~min}$ of baseline recording) and averaged into eight 5 min intervals, two before tetanus and six after tetanus. These pooled results were used for all analyses.

Results from both immunohistochemical and electrophysiological experiments were analyzed using an ANOVA design, with age and group as between-subjects factors. Repeated-measures analyses were used when appropriate, with recording interval as a within-subject factor. Post hoc analyses were performed using ANOVA for simple effects or Fisher's protected least square difference (PLSD) for pairwise comparisons.

\section{RESULTS}

\section{Behavior}

Behavioral results are given separately for the anatomical and physiological experiments. Figure $1 A$ shows the behavioral results from the anatomical studies expressed as a percent alternation. Alternation behavior increased over postnatal development $\left[F_{(2,30)}=10.16 ; p<0.0005\right]$, with P30 animals alternating more than the other groups ( $p<0.05$ by Fisher's PLSD). Only at P30 did performance on the Y-maze differ from that expected by chance $[50 \% ; t(10)=4.01 ; p<0.01]$. The level of exploratory activity, indicated by the number of arm entries, did not change with age (Fig. 1, inset).

The behavioral results were similar for the physiological studies (Fig. $1 B$ ). Again, there was a significant age effect $\left[F_{(2,26)}=5.14\right.$; $p<0.02$ ], with P30 animals alternating more than the other ages $(p<0.05$ by Fisher's PLSD). At P16 and P23, performance on the Y-maze did not differ significantly from that expected by chance $(50 \%)$. Significant alternation was observed at P30 $[t(8)=$ 5.90; $p<0.0005]$. In this case, P16 subjects were less active than those from the other two ages $\left[F_{(2,26)}=4.55 ; p<0.03\right]$; P23 and P30 animals did not differ $(p>0.5$, PLSD).

\section{Immunocytochemistry}

A comparison of FL-IR for all CON subjects indicated no change in baseline FL-IR over the 3-5 weeks of postnatal development for any area examined. A low level of baseline FL-IR was observed across the various age groups, consistent with previous reports examining basal Fos levels over postnatal development (Sakurai-Yamashita et al., 1991; Schreiber et al., 1992; Alcantara and Greenough, 1993; Pennypacker et al., 1993, 1994). There were no significant group or age effects for cells in area CA3 or 


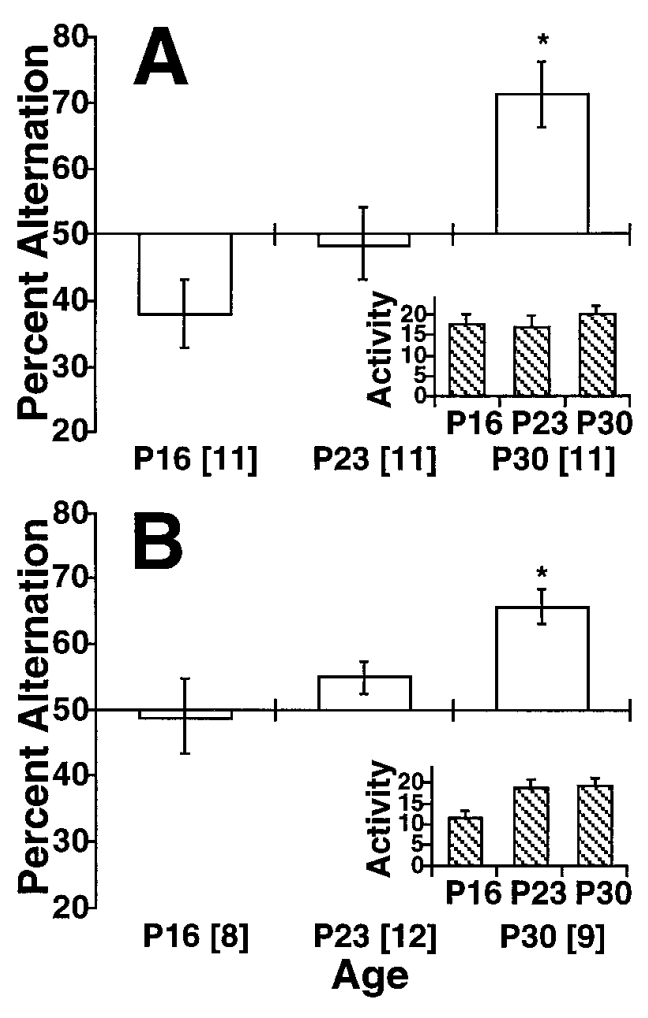

Figure 1. Performance on the Y-maze. Percent alternation $( \pm \mathrm{SEM})$ is given as a function of age for the immunohistochemical study $(A)$ and the electrophysiological study $(B)$ and is presented as a deviation from chance $(50 \%)$. An asterisk indicates significantly different from chance $(p<$ $0.05)$. Insets show activity (defined as the number of arms entered); $n$ values are given in brackets.

the granule cells of the dentate gyrus (Fig. $2 A, B$ ). However, in area CA1, the behavioral manipulation resulted in a significant age $\times$ group interaction $\left[F_{(2,60)}=10.22 ; p<0.0005\right]$, caused by a massive increase in FL-IR in P30 EXP subjects $[t(20)=3.95 ; p<$ 0.001; Fig. $2 C$ ]. An example of FL-IR in area CA1 of a P30 EXP subject is given in Figure 3.

A pattern of activity, similar to that observed in CA1, was observed for the subicular region $\left[F_{(2,60)}=4.43\right.$; $p<0.02$; Fig. $2 D]$; in the perisplenial cortex, the interaction approached significance $\left[F_{(2,56)}=2.83 ; p<0.07 ;\right.$ Fig. $\left.2 E\right]$. In both areas, only the P30 animals exhibited increased FL-IR. In contrast, for the PVT, there was a significant effect of group $\left[F_{(1,55)}=10.88 ; p<0.002\right.$; Fig. $2 F$ ], with experimental animals showing more FL-IR, and of age $\left[F_{(2,55)}=9.54 ; p<0.001\right]$. However, the group $\times$ age interaction was not significant.

\section{In vitro electrophysiology}

Results of the patterned stimulation on EPSP slope are presented in Figure 4 . There was a significant interaction of age $\times$ group $\times$ interval $\left[F_{(14,462)}=1.762 ; p<0.05\right]$, indicating that the EXP and CON groups did not respond to the tetanus similarly at all three ages. Analysis of simple effects showed that, in all groups, patterned stimulation produced significant LTP and that there were no significant effects or interactions of group at ages P16 and P23 $\left[F_{(7,126)}<1\right.$ for P16: $F_{(7,168)}=1.519, p>0.10$ for P23]. There was a significant effect of group $\times$ interval only among the P30 animals $\left[F_{(7,168)}=2.222 ; p<0.05\right]$, indicating that only in the P30 animals did environmental experience produce a decrease in LTP.

\section{DISCUSSION}

The current studies were designed to determine whether, like the sensory cortices, the hippocampus undergoes a postnatal sensitive period with increased sensitivity to environmental stimuli. The results do not support this hypothesis, however, and instead suggest that, before the emergence of behavioral function, hippocampal cellular activity is insensitive to environmental stimulation.

In the cortical sensory systems, postnatal sensitive periods have three main features. They begin before the onset of mature behavioral function, they are marked by susceptibility to synaptic plasticity, and neurons show responsiveness to environmental stimulation. Thus, before the cortex is functionally mature, stimulation produces increased cellular activity (Rosen et al., 1992; Beaver et al., 1993; Mower, 1994). This activity is thought to alter neuronal function via NMDA receptor (NMDAR) mechanisms, which are enhanced during this period (Kleinschmidt et al., 1987; Tsumato et al., 1987; Komatsu et al., 1988; Perkins and Teyler, 1988; Cline and Constantine-Paton, 1989; Bear et al., 1990). Activity dependent mechanisms then produce long-lasting influences on neural connectivity, which result in mature cortical organization and function (Shatz, 1990, 1996; Goodman and Shatz, 1993; Fox, 1995). In this way, environmentally stimulated neuronal activity determines the functional organization of the cortex.

The postnatal development of the hippocampus seems similar to that of the sensory cortices in two ways. First, in both systems, behavioral function is late to emerge. In the rat, performance on behavioral tasks that, in the adult, seem to require an intact hippocampus is severely impaired until after 3 weeks of age. These tasks include spontaneous alternation (Douglas, 1975), spatial learning (Rudy et al., 1987; Kraemer and Randall, 1995), conditioning to contextual cues (Rudy, 1993; Rudy and Morledge, 1994), and working memory (Green and Stanton, 1989). Before this age, the animals are able to perform control tasks that require similar sensory and motor abilities but do not seem to require the hippocampus, including simple cued learning on the Morris maze and single-cue conditioning. These previous results are replicated in the current study. In both experiments, spontaneous alternation was observed only in P30 animals; at younger ages, the subjects explored randomly. Second, the mechanisms for synaptic plasticity are present in the hippocampus, as in the visual cortex, during this postnatal period of behavioral impairment; potentiation in the hippocampus reaches or exceeds adult levels by P15 (Harris and Teyler, 1984; Muller et al., 1989; Bekenstein and Lothman, 1991). In the current study, adult-like LTP was observed in control animals at the youngest age (P16; Fig. 4). These experiments were designed to determine whether the developing hippocampus shared the third feature of developmental sensitive periods, increased responsiveness to environmental stimulation.

Increased responsiveness to environmental stimulation, however, does not seem to be a feature of the postnatal development of the hippocampus. The immediate early gene c-fos and its protein product Fos are considered markers of cellular activity (Dragunow and Faull, 1989; Sheng and Greenberg, 1990; Morgan and Curran, 1991; Sagar and Sharp, 1993). In the visual cortex, brief exposure to light induces a larger increase in Fos expression during the sensitive period (Rosen et al., 1992; Beaver et al., 1993; Mower, 1994); in the adult rat hippocampus, expression is induced by a number of environmental stimulations (Tischmeyer et al., 1990; Handa et al., 1993; Melia et al., 1994; Hess et al., 1995; 
Figure 2. FL-IR. Activation indices ( \pm SEM) are given for three ages (P16, P23, and P30) under two conditions [EXP (hatched bars) and CON (open bars)]. There were no significant effects of either age or group in area CA3 $(A)$ or the dentate $(B)$. In CA1 $(C)$, there was a significant interaction of age $\times$ group $\left[F_{(2,60)}=10.22 ; p<\right.$ $0.0005]$, because of an increase after the behavioral manipulation at P30. In the subiculum $(D)$, the manipulation also resulted in an increase in FL-IR at $\mathrm{P} 30\left[F_{(2,60)}=\right.$ $4.43 ; p<0.02]$. A similar, although nonsignificant, pattern was observed in the perisplenial cortex $\left[E ; F_{(2,56)}=2.83 ; p<\right.$ $0.07]$. In the PVT $(F)$, there was a significant effect of the manipulation, which did not interact with age. See Materials and Methods for $n$ values; an asterisk indicates significantly different from controls.
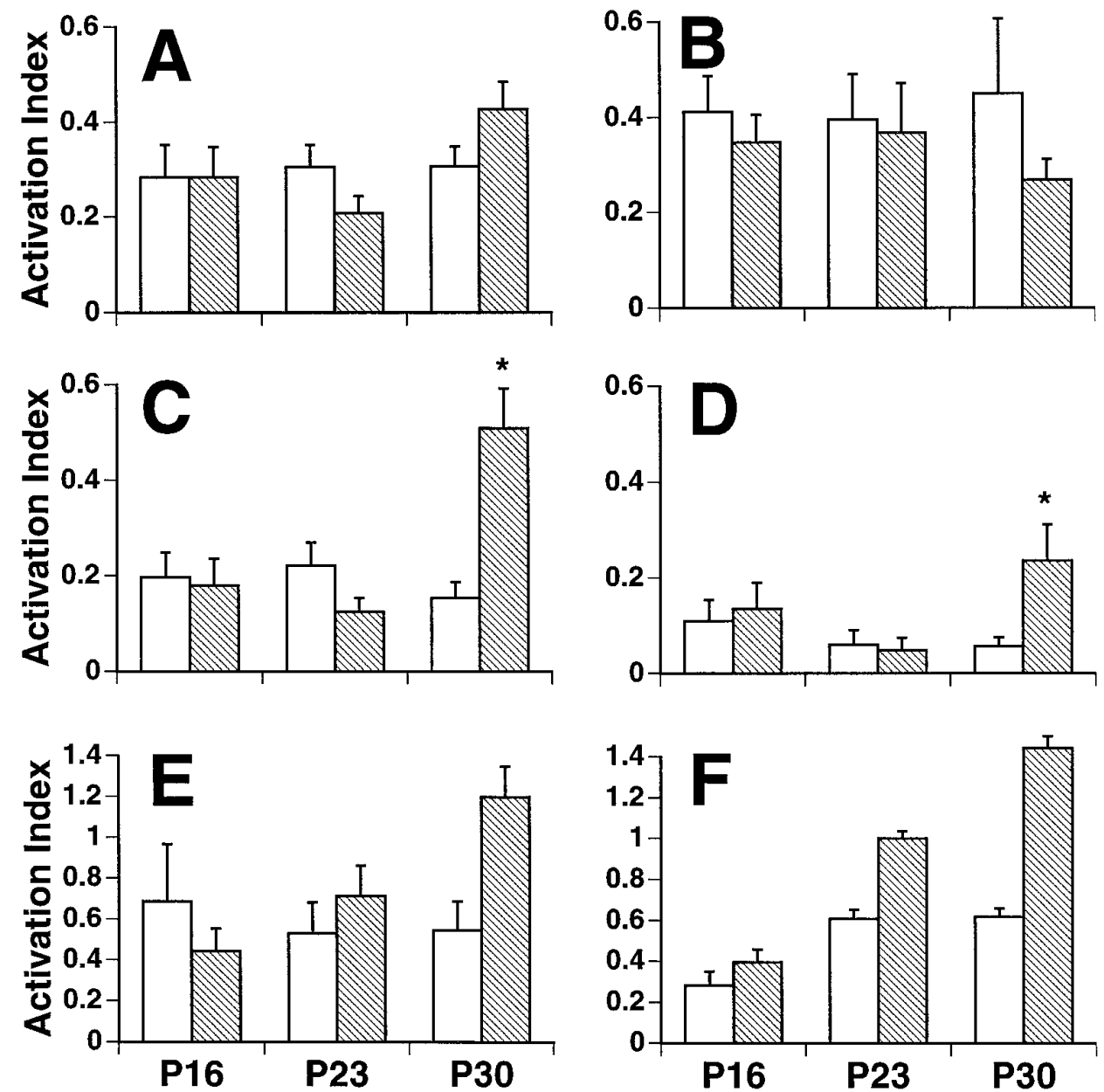

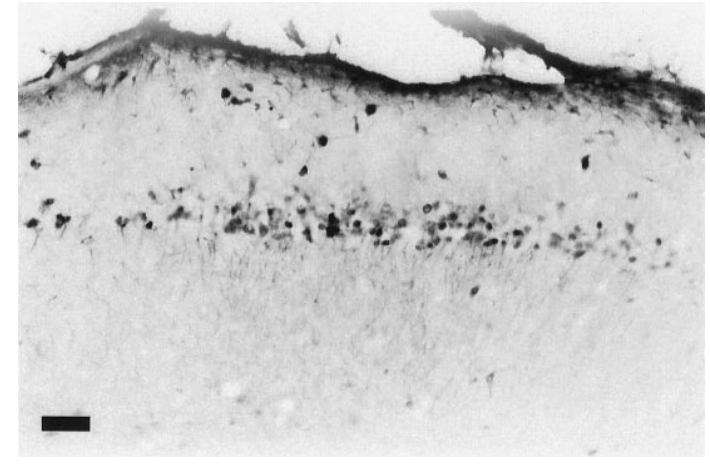

Figure 3. FL-IR. Photomicrograph of FL-IR in area CA1 of the hippocampus of a P30 EXP subject showing a small number of darkly stained cells. Scale bar, $60 \mu \mathrm{m}$.

Grimm and Tischmeyer, 1997). If the hippocampus undergoes a postnatal sensitive period, during which synaptic organization is influenced by environmental experience, then Fos expression after environmental stimulation should be increased during this period. The behavioral manipulation, testing in the Y-maze and exposure to a novel environment, was sufficient to induce Fos expression in area CA1 and the subiculum of P30 animals, after the emergence of alternation behavior. Although the significance of these locations is unclear, it may be related to developmental changes at the CA3-CA1 synapse (Dumas and Foster, 1995). However, rather than an increase of Fos expression in the imma- ture animals, a lack of staining was observed. The absence of Fos induction in the hippocampus is not caused by developmental limits in the biochemical processes for activity-induced Fos production, because Fos is expressed in the hippocampus by P7 and can be induced by seizure activity by P13 (Sakurai-Yamashita et al., 1991; Schreiber et al., 1992; Alcantara and Greenough, 1993; Pennypacker et al., 1993, 1994). These results suggest that the hippocampus undergoes an "insensitive period," during which it is isolated from environmental stimuli.

The results from the physiological studies support the conclusion that the hippocampus is insensitive to the environment during this period of postnatal development. In the sensory cortex, the extent to which LTP can be induced decreases with development, and the period of susceptibility to plasticity can be extended by deprivation (Kirkwood et al., 1996). In adult rats, treatments that involve stress or novelty reduce the extent to which LTP may be induced in the hippocampus (Foy et al., 1987; Shors et al., 1989; Diamond et al., 1990; Shors and Thompson, 1992; Shors and Dryver, 1993; Diamond and Rose, 1994; Foster et al., 1996). Although the functional significance of this reduction is unclear, recent evidence suggests that it is NMDAR dependent and can be reversed with long-term depression (Kim et al., 1996). In preliminary experiments, we found that our environmental manipulation was sufficient to reduce LTP in adult rats (N.S. Waters and T. C. Foster, unpublished observations). In the current experiment, the decrease in the amount of LTP observed after the environmental manipulation was taken as an index of 

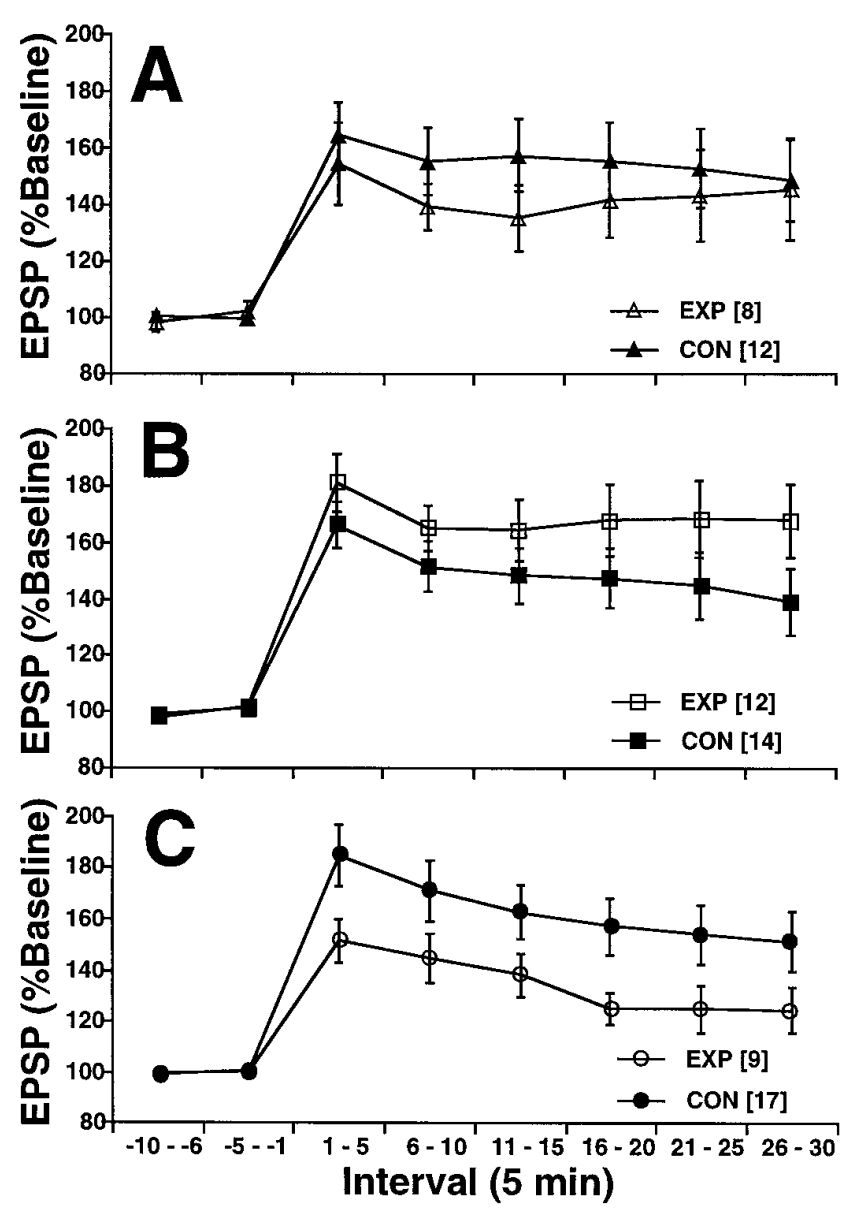

Figure 4. LTP. The EPSP slope is given as a percent of baseline $( \pm$ $\mathrm{SEM})$ as a function of time (in 5 min intervals) for P16 $(A), \mathrm{P} 23(B)$, and P30 $(C)$ subjects. Patterned stimulation occurred at time 0 . There was a significant interaction of age $\times$ group $\times$ interval $\left[F_{(14,462)}=1.762 ; p<\right.$ $0.05]$. Only at P30 did EXP differ from CON $(C)$. Values of $n$ are given in brackets.

hippocampal responsiveness to the environment. If an animal's hippocampus is reacting to the environment, then the environmental manipulation should produce a decrease in LTP, as seen in adult animals. Failure to decrease LTP indicates a nonresponsive hippocampus. Only the P30 animals had responsive hippocampi. Whether the decrease in LTP results from a lower capacity for potentiation or from an increase in baseline excitability is not clear from the present data. Previous studies have demonstrated increased baseline excitability in animals exposed to long-term enrichment manipulations (Green and Greenough, 1986; Foster et al., 1996). The decrease in LTP may be related to the increase in Fos expression, because both were elicited by the same manipulation and both are thought to be NMDAR dependent (Hisanaga et al., 1992; Kim et al., 1996). By both measures, stimulation failed to produce any effects before the onset of behavioral competence, suggesting that the hippocampus is not responsive to the environment during this period.

Neither experiment directly investigated the cause of the cellular activity in the older animals. Previous studies have found that hippocampal cellular discharge activity is influenced by a complex interaction of associative and contextual stimuli in the environmental (e.g., Foster et al., 1986, 1989; Eichenbaum et al.,
1989; Otto and Eichenbaum, 1992; Melia et al., 1994; Hess et al., 1995). The activity observed in these animals may be because of the processing of environmental stimuli, generalized effects of stress, or even motor activity. However, it is unlikely that motor activity would produce age-related differences because the subjects showed similar activity levels at all ages. The generalized stress response is usually found to be mature by P14 in rats (Shoenfield et al., 1980; Sapolsky and Meaney, 1986; Walker et al., 1991), before the earliest age tested here, and therefore would be unlikely to produce differential neuronal activity in the different age groups. The difference seems related to the type of behavior the animals engaged in, with the older rats exhibiting spatial working memory.

Whatever the source of the neuronal activity in behaviorally mature animals, most noticeable is its absence in the younger groups. Cellular responsiveness to the environment was not detected before the onset of behavioral function, using two very different measures. These results suggest that the development of the hippocampus does not depend on environmentally evoked activity. Although influences measured by methods other than either physiological responsiveness or Fos staining cannot be ruled out, the emergence of function in this system may be independent of environment and require spontaneous neural activity or chemical signals to determine synapse specificity, as seen in the early development of the visual system (Rakic, 1981; Shatz, 1990, 1996; Goodman and Shatz, 1993; Fox, 1995), or a novel mechanism, which has not been observed in the developing cortex. The mechanisms of postnatal development in the hippocampal system have important implications not only for the processes of normal and abnormal development but also for the mechanisms of cognitive function in adults. This relative independence of environmental influences is consistent with some models of hippocampal function, which propose that the hippocampus functions as a coordinate matrix of preconfigured synaptic contacts, which in the adult will more readily adapt to the variety of environments (McNaughton et al., 1996). The formation of such a network may be independent of the environment, because developmental dependence on environmental experience may limit the formation of synaptic configurations.

\section{REFERENCES}

Alcantara AA, Greenough WT (1993) Developmental regulation of FOS-related antigens in cerebral cortex, striatum, hippocampus, and cerebellum of the rat. J Comp Neurol 334:75-85.

Amaral DG, Dent JA (1981) Development of the mossy fibers of the dentate gyrus. I. A light and electron microscopic study of the mossy fibers and their expansions. J Comp Neurol 195:51-86.

Amaral DG, Kurz J (1985) The time of origin of cells demonstrating glutamic acid decarboxylase-like immunoreactivity in the hippocampal formation of the rat. Neurosci Lett 59:33-39.

Baudry M, Arst D, Oliver M, Lynch G (1981) Development of glutamate binding sites and their regulation by calcium in rat hippocampus. Dev Brain Res 1:37-48.

Bayer SA (1980) Development of the hippocampal region in the rat. I. Neurogenesis examined with ${ }^{3} \mathrm{H}$-thymidine autoradiography. J Comp Neurol 190:87-114.

Bear MF, Kleinschmidt A, Gu Q, Singer W (1990) Disruption of experience dependent synaptic modifications in striate cortex by infusion of an NMDA receptor antagonist. J Neurosci 10:909-925.

Beaver CJ, Mitchell DE, Robertson HA (1993) Immunohistochemical study of the pattern of rapid expression of c-fos protein in the visual cortex of dark-reared kittens following initial exposure to light. J Comp Neurol 333:469-484. 
Bekenstein JW, Lothman EW (1991) An in vivo study of the ontogeny of long-term potentiation (LTP) in the CA1 region and in the dentate gyrus of the rat hippocampal formation. Dev Brain Res 63:245-251.

Castro CA, Paylor R, Rudy JW (1987) A developmental analysis of the learning and short-term-memory processes mediating performance in conditional-spatial discrimination problems. Psychobiology 15:308-316.

Cline HT, Constantine-Paton M (1989) NMDA receptor antagonists disrupt the retinotectal topographic map. Neuron 3:413-426.

Crain B, Cotman C, Taylor D, Lynch G (1973) A quantitative electron microscopic study of synaptogenesis in the dentate gyrus of the rat. Brain Res 63:195-204.

Crair MC, Malenka RC (1995) A critical period for long-term potentiation at thalamocortical synapses. Nature 375:325-328.

Denenberg VH (1979) Analysis of variance procedures for estimating reliability and comparing individual subjects. In: Origins of the infant's social responsiveness (Thoman E, ed), pp 339-348. Hillsdale, NJ: Erlbaum.

Diamond DM, Rose GM (1994) Stress impairs LTP and hippocampal dependent memory. Ann NY Acad Sci 746:411-414.

Diamond DM, Bennett MC, Stevens KE, Wilson RL, Rose GM (1990) Exposure to a novel environment interferes with the induction of hippocampal primed burst potentiation in the behaving rat. Psychobiology 18:273-281.

Douglas RJ (1975) The development of hippocampal function: implications for theory and therapy. In: The hippocampus: Vol 2, Neurophysiology and behavior (Isaacson RL, Pribram KH, eds), pp 327-361. New York: Plenum.

Dragunow M, Faull R (1989) The use of c-fos as a metabolic marker in neuronal pathway tracing. J Neurosci Methods 29:261-265.

Dumas TC, Foster TC (1995) Developmental increase in CA3-CA1 presynaptic function in the hippocampal slice. J Neurophysiol 73:1821-1828.

Eichenbaum H, Wiener SI, Shapiro ML, Cohen NJ (1989) The organization of spatial coding in the hippocampus: a study of neural ensemble activity. J Neurosci 9:2764-2775.

Foster TC, Christian EP, Hampson RE, Campbell KA, Deadwyler SA (1986) Sequential dependencies regulate sensory evoked responses of single units in the rat hippocampus. Brain Res 408:86-96.

Foster TC, Castro CA, McNaughton BL (1989) Spatial selectivity of rat hippocampal neurons: dependence on preparedness for movement. Science 244:1580-1582.

Foster TC, Gagne J, Massicotte G (1996) Mechanisms of altered synaptic strength due to experience: relation to long-term potentiation. Brain Res 736:243-250.

Fox K (1995) The critical period for long-term potentiation in primary sensory cortex. Neuron 15:485-488.

Foy MR, Stanton ME, Levine S, Thompson RF (1987) Behavioral stress impairs long-term potentiation in rodent hippocampus. Behav Neural Biol 48:138-149.

Goodman CS, Shatz CJ (1993) Developmental mechanisms that generate precise patterns of neuronal connectivity. Cell 72/Neuron [Suppl] 10:77-98.

Green EJ, Greenough WT (1986) Altered synaptic transmission in the dentate gyrus of rats: evidence from hippocampal slices maintained in vitro. J Neurophysiol 55:739-750.

Green RJ, Stanton ME (1989) Differential ontogeny of working memory and reference memory in the rat. Behav Neurosci 103:98-105.

Grimm R, Tischmeyer W (1997) Complex patterns of immediate early gene induction in rat brain following brightness discrimination training and pseudotraining. Behav Brain Res 84:109-116.

Haas HL, Schaerer B, Vosmansky M (1979) A simple perfusion chamber for the study of nervous tissue slices in vitro. J Neurosci Methods 1:323-325.

Handa RJ, Nunley KM, Bollnow MR (1993) Induction of c-fos mRNA in the brain and anterior pituitary gland by a novel environment. NeuroReport 4:1079-1082.

Harris KM, Teyler TJ (1984) Developmental onset of long-term potentiation in area CA1 of the rat hippocampus. J Physiol (Lond) 346:27-48.

Hess US, Lynch G, Gall CM (1995) Changes in c-fos mRNA expression in rat brain during odor discrimination learning: differential involvement of hippocampal subfields CA1 and CA3. J Neurosci 15:4786-4795.

Hisanaga K, Sagar SM, Sharp FR (1992) $N$-Methyl-D-aspartate antagonists block fos-like protein expression induced via multiple signaling pathways in cultured cortical neurons. J Neurochem 58:1836-1844.
Kim JJ, Foy MR, Thompson RF (1996) Behavioral stress modifies hippocampal plasticity through $N$-methyl-D-aspartate receptor activation. Proc Natl Acad Sci USA 93:4750-4753.

Kirkwood A, Lee HK, Bear MF (1995) Co-regulation of long-term potentiation and experience dependent synaptic plasticity in visual cortex by age and experience. Nature 375:328-331.

Kirkwood A, Rioult MC, Bear MF (1996) Experience-dependent modification of synaptic plasticity in visual cortex. Nature 381:526-528.

Kleinschmidt A, Bear MF, Singer W (1987) Blockade of "NMDA" receptors disrupts experience dependent plasticity of kitten striate cortex. Science 238:355-358.

Komatsu Y, Fujii K, Maeda J, Sakaguchi H, Toyama K (1988) Longterm potentiation of synaptic transmission in kitten visual cortex. J Neurophysiol 59:124-141.

Kraemer PJ, Randall CK (1992) Latent inhibition in preweanling rats. Psychobiology 20:81-84.

Kraemer PJ, Randall CK (1995) Spatial learning in preweanling rats trained on a Morris water maze. Psychobiology 23:144-152.

McNaughton BL, Barnes CA, Gerrard JL, Gothard K, Jung MW, Knierim JJ, Kudrimoti H, Qin Y, Skaggs WE, Suster M, Weaver KL (1996) Deciphering the hippocampal polyglot: the hippocampus as a path integration system. J Exp Biol 199:173-185.

Melia KR, Ryabinn AE, Schroeder R, Bloom FE, Wilson MC (1994) Induction and habituation of immediate early gene expression in rat brain by acute and repeated restraint stress. J Neurosci 14:5929-5938.

Morgan JI, Curran T (1991) Stimulus-transcription coupling in the nervous system: involvement of the inducible proto-oncogenes fos and jun. Annu Rev Neurosci 14:421-451.

Mower GD (1994) Differences in the induction of Fos protein in cat visual cortex during and after the critical period. Mol Brain Res 21:47-54.

Moye TB, Rudy JW (1985) Ontogenesis of learning: VI. Learned and unlearned responses to visual stimulation in the infant hooded rat. Dev Psychobiology 18:395-409.

Muller D, Oliver M, Lynch G (1989) Developmental changes in synaptic properties of neonatal rats. Dev Brain Res 49:105-114.

Otto T, Eichenbaum H (1992) Neuronal activity in the hippocampus during delayed non-matching to sample performance in rats: evidence for hippocampal processing in recognition memory. Hippocampus 2:323-334.

Pennypacker KR, Dreyer D, Hong JS, McMillian MK (1993) Elevated basal AP-1 DNA binding activity in developing rat brain. Mol Brain Res 19:349-352.

Pennypacker KR, McMillian MK, Douglass J, Hong JS (1994) Ontogeny of kainate-induced gene expression in rat hippocampus. J Neurochem 62:438-444.

Perkins IV AT, Teyler TJ (1988) A critical period for long-term potentiation in the developing rat visual cortex. Brain Res 439:222-229.

Rakic P (1981) Development of visual centers in the primate brain depends on binocular competition before birth. Science 214:928-931.

Rosen KM, McCormack MA, Villa-Komaroff L, Mower GD (1992) Brief visual experience induces immediate early gene expression in the cat visual cortex. Proc Natl Acad Sci USA 89:5437-5441.

Rudy JW (1993) Contextual conditioning and auditory cue conditioning dissociate during development. Behav Neurosci 107:887-891.

Rudy JW, Morledge P (1994) Ontogeny of contextual fear conditioning in rats: implications for consolidation, infantile amnesia, and hippocampal system function. Behav Neurosci 108:227-234.

Rudy JW, Stadler-Morris S, Albert P (1987) Ontogeny of spatial navigation in the rat: dissociation of "proximal" and "distal"-cue based behaviors. Behav Neurosci 101:62-73.

Sagar SM, Sharp FR (1993) Early response genes as markers of neuronal activity and growth factor action. Adv Neurol 59:273-284.

Sakurai-Yamashita Y, Sassone-Corsi P, Gombos G (1991) Immunohistochemistry of c-fos in mouse brain during postnatal development: basal levels and changing response to metrazol and kainate injection. Eur J Neurosci 3:764-770.

Sapolsky RM, Meaney MJ (1986) Maturation of the adrenocortical stress response: neuroendocrine control mechanisms and the stress hyporesponsive period. Brain Res Rev 11:65-76.

Schoenfield NM, Leathem JH, Rabii J (1980) Maturation of adrenal stress responsiveness in the rat. Neuroendocrinology 31:101-105.

Schreiber SS, Tocco G, Nahm I, Finch CE, Johnson SA, Baudry M (1992) Absence of c-fos induction in neonatal rat brain after seizures. Neurosci Lett 136:31-35. 
Shatz CJ (1990) Impulse activity and the patterning of connections during CNS development. Neuron 5:745-756.

Shatz CJ (1996) Emergence of order in visual system development. Proc Natl Acad Sci USA 93:602-608.

Sheng M, Greenberg ME (1990) The regulation and function of c-fos and other immediate early genes in the nervous system. Neuron 4:477-485.

Shors TJ, Dryver E (1993) Effects of stress and long-term potentiation (LTP) on subsequent LTP and theta-burst response in the dentate gyrus. Brain Res 666:232-238.

Shors TJ, Thompson RF (1992) Acute stress impairs (or induces) synaptic long-term potentiation (LTP) but does not affect paired pulse facilitation in the stratum radiatum of rat hippocampus. Synapse 11:262-265.

Shors TJ, Seib TB, Levine S, Thompson RF (1989) Inescapable versus escapable shock modulates long-term potentiation in the rat hippocampus. Science 244:224-226.

Stirling RV, Bliss TVP (1978) Hippocampal mossy fiber development at the ultrastructural level. Prog Brain Res 48:191-198.

Tischmeyer W, Kaczmarek L, Strauss M, Jork R, Matthies H (1990) Accumulation of c-fos mRNA in rat hippocampus during acquisition of a brightness discrimination. Behav Neural Biol 54:165-171.

Tsumoto T, Hagihara K, Sato H, Hata Y (1987) NMDA receptors in the visual cortex of young kittens are more effective than those of adult cats. Nature 327:513-514.

Walker C-D, Scribner KA, Cascio CS, Dallman MF (1991) The pituitary-adrenocortical system of neonatal rats is responsive to stress throughout development in a time-dependent and stressor-specific fashion. Endocrinology 128:1385-1395. 